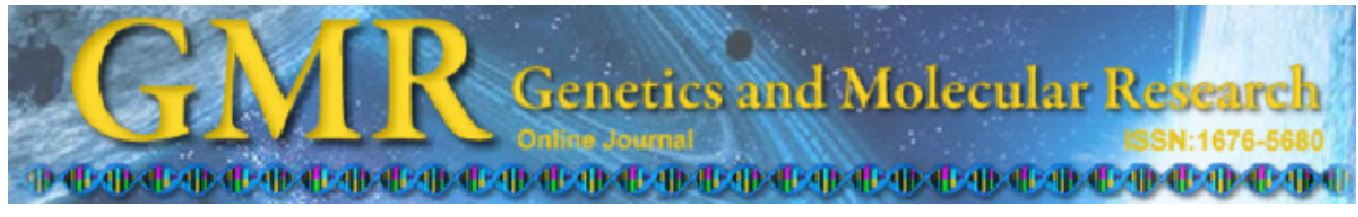

\title{
Interleukin-8 expression associated with canine mammary tumors
}

\author{
D.A.P.C. Zuccari ${ }^{1,2}$, R. Castro ${ }^{3}$, G.B. Gelaleti ${ }^{2}$ and U.M. Mancini ${ }^{4}$ \\ ${ }^{1}$ Faculdade de Medicina de São José do Rio Preto, São José do Rio Preto, SP, Brasil \\ ${ }^{2}$ Programa de Pós-Graduação em Genética, \\ Universidade Estadual Paulista "Júlio de Mesquita Filho", \\ São José do Rio Preto, SP, Brasil \\ 3Programa de Pós-Graduação em Ciências da Saúde, \\ Faculdade de Medicina de São José do Rio Preto, São José do Rio Preto, SP, Brasil \\ ${ }^{4}$ Instituto de Biociências, Universidade de São Paulo, São Paulo, SP, Brasil
}

Corresponding author: D.A.P.C. Zuccari

E-mail: debora.zuccari@famerp.br

Genet. Mol. Res. 10 (3): 1522-1532 (2011)

Received January 7, 2011

Accepted June 23, 2011

Published August 1, 2011

DOI 10.4238/vol10-3gmr1145

ABSTRACT. The use of prognostic markers for mammary cancer
is important for routine diagnosis and research. Interleukin-8 (IL-8)
is a chemotactic cytokine, produced by several cell types in response
to inflammation. The expression, regulation and function of IL- 8 in
dogs are little known. Recent studies have associated angiogenesis
and inflammatory processes with tumor malignancy. We investigated
a possible correlation between IL-8 expression and mammary tumor
prognosis in female dogs. IL-8 expression was measured in 50 dogs
with mammary neoplasia by immunohistochemistry and real-time PCR.
Immunohistochemical staining was done with anti-IL- 8 antibodies and
PCR amplifications were performed in a 7500 Fast Real-Time PCR
system. Gene expression stability was analyzed by the geNorm software.
Quantitative real-time PCR showed that IL-8 expression decreased in
malignant mammary cells compared to normal mammary tissue, while
weak immunostaining was associated with a diagnosis of carcinoma.
Complementing earlier studies on IL- 8 expression in several types of 
cancer, including mammary cancer, we conclude that IL-8 has potential for use as a prognostic marker for canine mammary neoplasia.

Key words: Interleukin-8; Mammary cancer; Immunohistochemistry; Real-time PCR; Prognosis

\section{INTRODUCTION}

Mammary neoplasms are the most common tumor type in female dogs, accounting for nearly 52\% of the neoplasms (MacEwen, 1990; Sorenmo, 1998; Queiroga and Lopes, 2002; Zuccari et al., 2001, 2008). Mammary tumors in bitches challenge clinicians and pathologists because they have controversial nomenclature and classification, which hinders comparative studies (Brodey et al., 1983; Queiroga and Lopes, 2002).

The role of inflammation and inflammatory cells in tumor development and progression has been increasingly studied. Both tumor cells and cells participating in inflammation produce cytokines and chemokines, which mediate many aspects of inflammation and profoundly affect the development of chronic diseases, including cancer (Snoussi et al., 2006). Interleukin-8 (IL-8) is a chemokine (chemotactic cytokine) produced by monocytes, lymphocytes, endothelial cells and epithelial cells, fibroblasts and a range of other cells in response to stimuli such as lipopolysaccharides from Gram-negative bacteria and other cytokines (e.g., TNF- $\alpha$ and IL-1B) (Moulton, 1990). Breast cancer tissues have been shown to express high levels of IL-8 (Snoussi et al., 2006).

Chemokines can control the natural evolution of inflammatory responses by recruiting specific effector cells. Cytokine production at the inflammation site is constant and thus important for the development of chronic diseases such as cancers (Wahl and Kleinman, 1998).

IL-8 is a potent chemoattractant and activator of neutrophils and lymphocytes (Monton et al., 1997; Snoussi et al., 2006). It produces proinflammatory effects in response to many human tumor types, such as ovarian, lung, urinary bladder, prostate and pancreas cancers, as well as head and neck squamous carcinoma and melanoma. IL-8 has been shown to enhance breast cancer progression through mitogenic and angiogenic properties (Snoussi et al., 2006).

IL-8 is a key factor in tumor angiogenesis ( $\mathrm{Li}$ et al., 1998). It acts along with vascular endothelial growth factor (VEGF) and eukaryotic initiation factor (eIF4E) (Zhou et al., 2006). In addition, cyclooxygenase-2 (COX-2) increases the invasiveness of breast cancer through IL-8 activation (Simeone et al., 2007).

Besides promoting angiogenesis, IL-8 has a strong relationship with the metastatic phenotype and reinforces the potential of breast tumor cells (De Larco et al., 2003; Bobrovnikova-Marjon et al., 2004). This action is facilitated in mammary tissue because this tissue is well supported with blood vessels (De Larco et al., 2001). IL-8 occurrence in breast tumors may also trigger bone metastasis (Schwaninger et al., 2007).

IL-8 is related to a series of factors including hormonal features, postoperative conditions and tumor type. For instance, the role of IL-8 in the development and progression of human breast cancer is associated with high estrogen expression, and the determination of the estrogen receptor level in the tumor is a good prognostic tool (Li et al., 1998; Vazquez-Martin et al., 2007). IL-8 is also correlated with progesterone receptors and c-erB-2 (Yao et al., 2007). Following surgery, IL-8 levels increase in breast cancer patients 2 weeks postoperative (Schmidt et 
al., 2007). High levels of IL-8 are also used to confirm tumor aggressiveness (Zhou et al., 2006).

In contrast to the studies reported, Lee et al. (2000) suggest that IL-8 can retard ovarian tumor growth in humans. The constitutive expression of IL-8 in human ovarian tumors caused low tumor development in nude mice. This attenuation in tumor growth was correlated with neutrophil and monocyte infiltration.

Knowledge of the expression, regulation and function of IL-8 in dogs is limited. Recent studies deal with inflammatory and angiogenic factors associated with tumor malignancy and indicate that IL-8 expression may be used to predict prognosis (Perez et al., 2000; van't Veer et al., 2005).

Although tumor prognosis assessment is complex, the data on individual parameters may prove to be helpful (Thomas and Berner, 2000). Interleukin-8 expression patterns have not been reported in canine mammary tumors, and the aim of this study was to evaluate IL- 8 expression in these tumors and to determine its value as a prognostic marker.

\section{MATERIAL AND METHODS}

\section{Specimens}

Specimens of 50 mammary tumors were surgically removed from pure and crossbreed bitches aged between 2 and 17 years (mean age $=10$ years). According to an already described model (Sorenmo et al., 2009; Ferreira et al., 2009), the staging tests included routine blood analysis (complete blood count, serum chemistry profile), urinalysis, fine needle aspirates of palpable draining lymph nodes, and thoracic radiological examinations. The mammary glands were examined carefully and all tumors were recorded and measured. The surgical resection was performed according to standard practice, with the aim of removing all of the tumor/tumors with complete margins. The type of surgery, that is lumpectomy, simple mastectomy or regional mastectomy, depended on the tumor size, location and the number of tumors present in each individual dog. If necessary, the surgeries were staged in two phases in order to prevent excessive tissue tension and wound dehiscence in dogs with multiple large tumors. All tumors were submitted to histopathological examination. Two independent pathologists performed the evaluations blinded to each other and all clinical information about the case. The tumors were classified according to the type of tissue present (epithelial, myoepithelial and/or connective tissue) and whether they were malignant or benign. The malignant simple epithelial tumors were grouped together as carcinomas for the purpose of this study and included tubulopapillary carcinoma, solid carcinomas and complex carcinomas. The diagnosis also included histopathological assessment of the entire section including dysplastic changes and was not limited to only the neoplastic changes. The animals were followed for 18 months and the survival time was defined as the period (days) between surgical tumor removal and date of death caused by the disease (end point). The cause of death was confirmed by clinical data (Table 1). The dogs were diagnosed with metastasis or recurrence confirmed by chest X-ray, abdominal ultrasound, needle aspiration biopsy of the new lump, or necropsy post mortem.

Two specimens were collected from each animal. The specimen used in the molecular assays was frozen immediately after surgery, and the specimen for immunohistochemistry was fixed in $10 \%$ buffered formaldehyde solution. Tissue blocks were prepared by standard histological methods, embedded in paraffin wax, sectioned at $3 \mu \mathrm{m}$ and stained with hematoxylin and eosin 
(HE). Representative areas of the tumor were selected for immunohistochemistry.

The histopathological classification was based on the Armed Forces Institute of Pathology by Misdorp et al. (1999). Histological grading was performed on HE-stained sections. According to the method of Elston and Ellis (1998), the grade for each case was derived from an assessment of 1) tubule formation, 2) nuclear pleomorphism, and 3) mitotic counts, each feature being scored 1 to 3 points. The scores were then summed to obtain the tumor grade, as follows: 3-5 points, well-differentiated carcinoma (grade I); 6-7 points, moderately differentiated carcinoma (grade II); 8-9 points, poorly differentiated carcinoma (grade III).

A previously established histological grading system for human breast carcinomas was used and tumors were grouped into three malignancy degrees based on cell malignancy criteria.

\section{Interleukin-8 immunostaining}

Immunohistochemistry was based on mouse monoclonal anti-human IL-8 antibody (G265-8) (BD Pharmigen, San Diego, CA, USA) diluted 1:50 in bovine serum albumin (BSA). A section from at least one representative block of each case was mounted onto silanized slides. Afterward, the slides were deparaffinized, rehydrated in graded alcohols, and incubated with $3 \%$ hydrogen peroxidase for 30 min to block endogenous peroxidase activity. Induced antigen retrieval in Pan Steam at $95^{\circ} \mathrm{C}$ with citric acid, $\mathrm{pH}$ 6.0, $35 \mathrm{~min}$, was used. After cooling, the slides were covered with BSA for $30 \mathrm{~min}$ before incubation with primary antibody for $2 \mathrm{~h}$ at room temperature and avidin-biotin-peroxidase complex $(\mathrm{ABC})$ for $1 \mathrm{~h}$. A dose of 5\% chromogen 3,3' diaminobenzidine tetrahydrochloride (Signet, Laboratories, Dedham, MA, USA) diluted in phosphate-buffered saline (PBS) was applied to the slides for $2-5 \mathrm{~min}$ at $20-22^{\circ} \mathrm{C}$. The slides were counterstained with Harris hematoxylin. Negative controls were obtained by omitting the primary antibody, whereas normal mammary gland tissue served as internal positive control in every assay. Marker expression was determined based on the semiquantative score system proposed by Allred et al. (1998).

\section{Immunohistochemical evaluation}

Multiple fields were examined in each slide and positive immunostaining was indicated by distinct brown cytoplasmic staining. Immunohistochemical examination was blind (i.e., without knowledge of the histopathological diagnosis) and the results were based on the consensus of at least two observers. A total of 1000 cells were evaluated in 10 fields (400X magnification) to assess positive cell percentage. The results were grouped into semiquantitative scores (SQS) as negative, focal ( $<10 \%$ positive cells; PC), weak (10-25\% PC), moderate $(25-50 \% \mathrm{PC})$, or strong $(>50 \% \mathrm{PC})$.

\section{Quantitative real-time polymerase chain reaction (PCR)}

Real-time PCR was performed in triplicate using an ABI Prism 7500 Sequence Detection System (Applied Biosystems, Foster City, CA, USA). Briefly, the reactions were performed in $20 \mu \mathrm{L}$ with $10 \mu \mathrm{L}$ Power SYBR Green PCR Master Mix (Applied 
Biosystems), $250 \mathrm{nM}$ of each primer and $10 \mathrm{ng} \mathrm{cDNA}$. The PCR conditions were $50^{\circ} \mathrm{C}$ for $2 \mathrm{~min}, 95^{\circ} \mathrm{C}$ for $10 \mathrm{~min}$ followed by 35 cycles at $95^{\circ} \mathrm{C}$ for $15 \mathrm{~s}$, and $60^{\circ} \mathrm{C}$ for $1 \mathrm{~min}$. Following PCR, dissociation curve analysis was performed to confirm the desired single gene product: 1 cycle of $95^{\circ} \mathrm{C}$ for $15 \mathrm{~s}, 60^{\circ} \mathrm{C}$ for $1 \mathrm{~min}$, and $95^{\circ} \mathrm{C}$ for $15 \mathrm{~s}$. To normalize each transcript level, it was divided by the expression values of HPRT1 used as internal control. Transcript level was calculated using the $2^{-\Delta \Delta C t}$ method (Livak and Schmittgen, 2001), where $\Delta \mathrm{Ct}$ was the difference between the threshold cycles of a target and the internal controls and $\Delta \Delta \mathrm{Ct}$ was the difference between the average $\Delta \mathrm{Ct}$ of the sample and the average $\Delta \mathrm{Ct}$ of the calibrator sample. The fold difference (relative abundance) was calculated using the formula $2^{-\Delta \Delta \mathrm{Ct}}$ and was plotted as mean $\pm \mathrm{SD}$ for $\mathrm{N}=3$ technical replicates. Fold differences of $>3$ were considered to be significant.

Every reaction had one negative and one positive control. Experiments were repeated when the coefficient of variation was higher than $5 \%$.

For amplifications, we used the primers IL-8 sense (5'GTCCAGGCACACCTCATTTC3') and antisense (5'GGCAGCTTTTGTCCTTTCTG3'), and HPRT1, sense (5'TTA TAG TCA AGG GCA TAT CC3') and antisense (5'AGC TTG CTG GTG AAA AGG AC3').

\section{Statistical analysis}

Multivariate logistic regression analyses of prognostic factors were performed. Results were analyzed on the basis of tumor diagnosis and patient outcome using immunoreactivity determined by analysis of dependence (Cordeiro, 1987). Intergroup differences were assessed by the Student $t$-test. $\mathrm{P}<0.05$ was considered to be significant (two-tail tests). All statistical tests were performed using the Microsoft office XP software (Minitab, version 12.22).

\section{RESULTS}

The histopathological evaluation showed that carcinoma was the predominant tumor type (44 animals/88\%). Of the 5 benign tumors (10\%), 2 were complex adenoma, 2 were adenomas and 1 was a ductal hyperplasia. One animal (2\%) had a fibrosarcoma. Five carcinomas were classified as carcinosarcoma based on the presence of cellular malignancy criteria in both parts (Table 1).

Simple carcinoma was the most common type detected in 30 animals, whereas 9 animals had complex carcinoma. The simple carcinomas included tubulopapillary, solid and anaplastic according to the Armed Forces Institute of Pathology by Misdorp et al. (1999).

From the histological grade, 34\% (15/44) of carcinomas were found to be grade I, $63.7 \%$ (28/44) grade II and 2.3\% (1/44) grade III. Comparing the findings of histopathological classification, grade I showed a higher prevalence of tubulopapillary carcinomas (6/15) followed by complex carcinomas; in grade II, there was a higher prevalence of tubulopapillary (11/28) followed by solid carcinoma, and in grade III, we found one solid carcinoma. The percentages of animals that died after the follow-up time and recurrence were $20.0 \%$ of grade I (3/15), $57.1 \%$ of grade II (16/28), $100 \%$ of grade III (1/1).

The immunohistochemical study showed independent staining distribution. A comparison between the overall survival time and the immunohistochemical staining demonstrated a statistically positive concordance (Fisher test, $\mathrm{P}=0.004$ ), and $66.67 \%$ of the survivors showed moderate to strong IL-8 staining (Table 2). Intense and cytoplasmic antibody staining was 
Table 1. Immunohistochemistry, molecular expression, histopathological diagnosis, grade, disease outcome, and disease-free interval in canine mammary tumors.

\begin{tabular}{|c|c|c|c|c|c|c|}
\hline Sample & Immunohistochemistry & Real-time PCR & Histopathological diagnosis & *Grade & Disease outcome & Disease-free interval \\
\hline 1 & Focal & Under & Carcinosarcoma & I & Death-euthanasia & $<6$ months \\
\hline 2 & Weak & Under & Tubulopapillary carcinoma & II & Death-metastasis & 6 to 18 months \\
\hline 3 & Focal & Under & Carcinosarcoma & II & Death-metastasis & $<6$ months \\
\hline 4 & Focal & Under & Tubulopapillary carcinoma & I & Survival & $>18$ months \\
\hline 5 & Weak & Under & Solid carcinoma & II & Death-metastasis & 6 to 18 months \\
\hline 6 & Focal & Under & Complex carcinoma & I & Survival-recurrence & $>18$ months \\
\hline 7 & Moderate & Under & Solid carcinoma & II & Death-recurrence & $>18$ months \\
\hline 8 & Focal & Under & Fibrosarcoma & - & Survival & $>18$ months \\
\hline 9 & Focal & Under & Tubulopapillary carcinoma & II & Death-euthanasia & $>18$ months \\
\hline 10 & Moderate & Under & Adenoma & - & Survival & $>18$ months \\
\hline 11 & Focal & Under & Complex carcinoma & II & Death-metastasis & $<6$ months \\
\hline 12 & Focal & Under & Solid carcinoma & II & Death-metastasis & $<6$ months \\
\hline 13 & Moderate & Under & Solid carcinoma & II & Death & $>18$ months \\
\hline 14 & Moderate & Under & Complex carcinoma & $\mathrm{I}$ & Survival & $>18$ months \\
\hline 15 & Weak & Under & Solid carcinoma & II & Death-metastasis & $>18$ months \\
\hline 16 & Strong & Under & Solid carcinoma & I & Death-metastasis & 6 to 18 months \\
\hline 17 & Focal & Under & Tubulopapillary carcinoma & II & Survival & $>18$ months \\
\hline 18 & Focal & Under & Tubulopapillary carcinoma & II & Death & 6 to 18 months \\
\hline 19 & Focal & Under & Solid carcinoma & II & Survival & $>18$ months \\
\hline 20 & Moderate & Under & Complex adenoma & - & Survival & $>18$ months \\
\hline 21 & Focal & Under & Solid carcinoma & III & Death-recurrence & $<6$ months \\
\hline 22 & Focal & Under & Complex adenoma & - & Survival & $>18$ months \\
\hline 23 & Focal & Under & Solid carcinoma & II & Death & $<6$ months \\
\hline 24 & Focal & Under & Tubulopapillary carcinoma & II & Survival & $>18$ months \\
\hline 25 & Focal & Under & Tubulopapillary carcinoma & II & Death-recurrence & $>18$ months \\
\hline 26 & Weak & Under & Complex carcinoma & I & Survival & $>18$ months \\
\hline 27 & Focal & Under & Complex carcinoma & II & Death-metastasis & $>18$ months \\
\hline 28 & Moderate & Under & Tubulopapillary carcinoma & $\mathrm{I}$ & Survival-recurrence & $>18$ months \\
\hline 29 & Moderate & Under & Tubulopapillary carcinoma & II & Death-recurrence & $<18$ months \\
\hline 30 & Focal & Under & Solid carcinoma & II & Survival & $>18$ months \\
\hline 31 & Strong & Under & Complex carcinoma & $\mathrm{I}$ & Death-recurrence & 6 to 18 months \\
\hline 32 & Strong & Under & Tubulopapillary carcinoma & I & Survival & $>6$ months \\
\hline 33 & Focal & Under & Tubulopapillary carcinoma & I & Survival & $>18$ months \\
\hline 34 & Moderate & Over & Complex carcinoma & II & Survival & $>18$ months \\
\hline 35 & Moderate & Under & Adenoma & - & Survival & $>18$ months \\
\hline 36 & Strong & Under & Carcinosarcoma & I & Survival & $>18$ months \\
\hline 37 & Strong & Under & Solid carcinoma & II & Survival & $>18$ months \\
\hline 38 & Strong & Under & Complex carcinoma & I & Survival & $>18$ months \\
\hline 39 & Moderate & Under & Tubulopapillary carcinoma & II & Survival & $>18$ months \\
\hline 40 & Weak & Under & Complex carcinoma & II & Death-euthanasia & $<18$ months \\
\hline 41 & Moderate & Under & Carcinosarcoma & II & Survival & $>18$ months \\
\hline 42 & Moderate & Under & Tubulopapillary carcinoma & II & Survival & $>18$ months \\
\hline 43 & Moderate & Over & Tubulopapillary carcinoma & I & Survival & $>18$ months \\
\hline 44 & Strong & Under & Tubulopapillary carcinoma & II & Survival & $>18$ months \\
\hline 45 & Strong & Under & Solid carcinoma & $\mathrm{I}$ & Survival & $<6$ months \\
\hline 46 & Moderate & Under & Solid carcinoma & II & Survival & $>18$ months \\
\hline 47 & Moderate & Over & Tubulopapillary carcinoma & I & Survival & $>18$ months \\
\hline 48 & Strong & Under & Ductal hyperplasia & - & Survival & $>18$ months \\
\hline 49 & Weak & Under & Carcinosarcoma & II & Death-metastasis & $<18$ months \\
\hline 50 & Moderate & Under & Tubulopapillary carcinoma & II & Survival & $>18$ months \\
\hline
\end{tabular}

*Histological grades according to Elston and Ellis (1998).

observed for the entire group (Figure 1). Moderate to strong immunohistochemical expression of IL- 8 was found in 4 of the 5 benign tumors analyzed.

The bands formed were $208 \mathrm{bp}$ in the molecular assays, and the samples studied had the quantitative score needed for evaluation. Real-time PCR used in the molecular analysis to quantitatively measure the IL-8 gene expression confirmed its underexpression in $94 \%$ of the tumor samples (Figure 2) compared to the normal tissue pool used as control. 


\begin{tabular}{|c|c|c|c|}
\hline \multirow[t]{2}{*}{ IL-8 staining } & \multicolumn{3}{|c|}{ Overal survival } \\
\hline & Alive & Dead & All \\
\hline Focal to weak & $\begin{array}{l}10 \\
40 \\
33.33 \%\end{array}$ & $\begin{array}{l}15 \\
60 \\
75.0 \%\end{array}$ & $\begin{array}{c}25 \\
100 \\
50.0 \%\end{array}$ \\
\hline Moderate to strong & $\begin{array}{l}20 \\
80 \\
66.67 \%\end{array}$ & $\begin{array}{c}5 \\
20 \\
25.0 \%\end{array}$ & $\begin{array}{c}25 \\
100 \\
50.0 \%\end{array}$ \\
\hline All & $\begin{array}{c}30 \\
60 \\
100.0 \%\end{array}$ & $\begin{array}{c}20 \\
40 \\
100.0 \%\end{array}$ & $\begin{array}{c}50 \\
100 \\
100.0 \%\end{array}$ \\
\hline
\end{tabular}

Chi-square $=8.333$; degrees of freedom $=1 ; \mathrm{P}=0.004$.
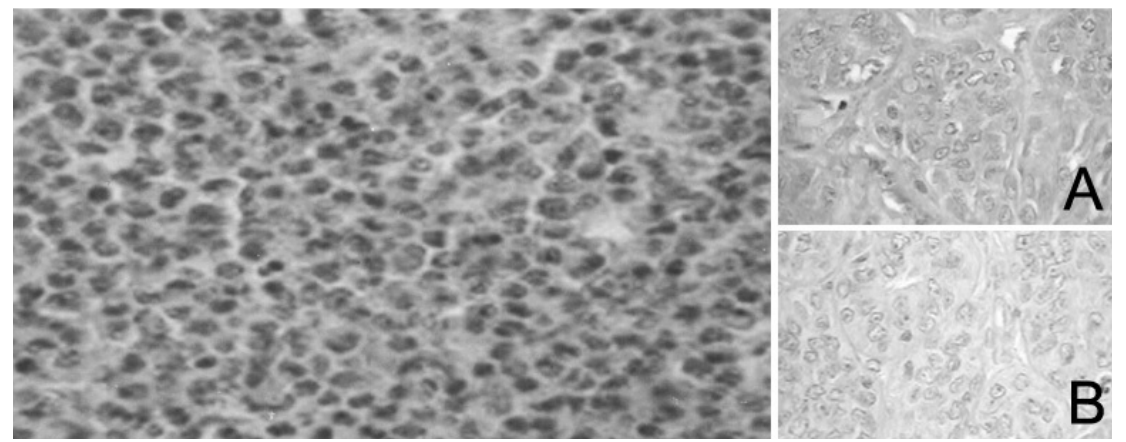

Figure 1. Photomicrography with strong staining for anti-interleukin-8 (IL-8). Induced antigen retrieval in Pan Steam with citric acid. Anti-human IL-8 antibody (BD Pharmigen) 1:50. Avidin-biotin-peroxidase method, LSAB, objective 400X. Controls: $\mathrm{A}=$ positive; $\mathrm{B}=$ negative.

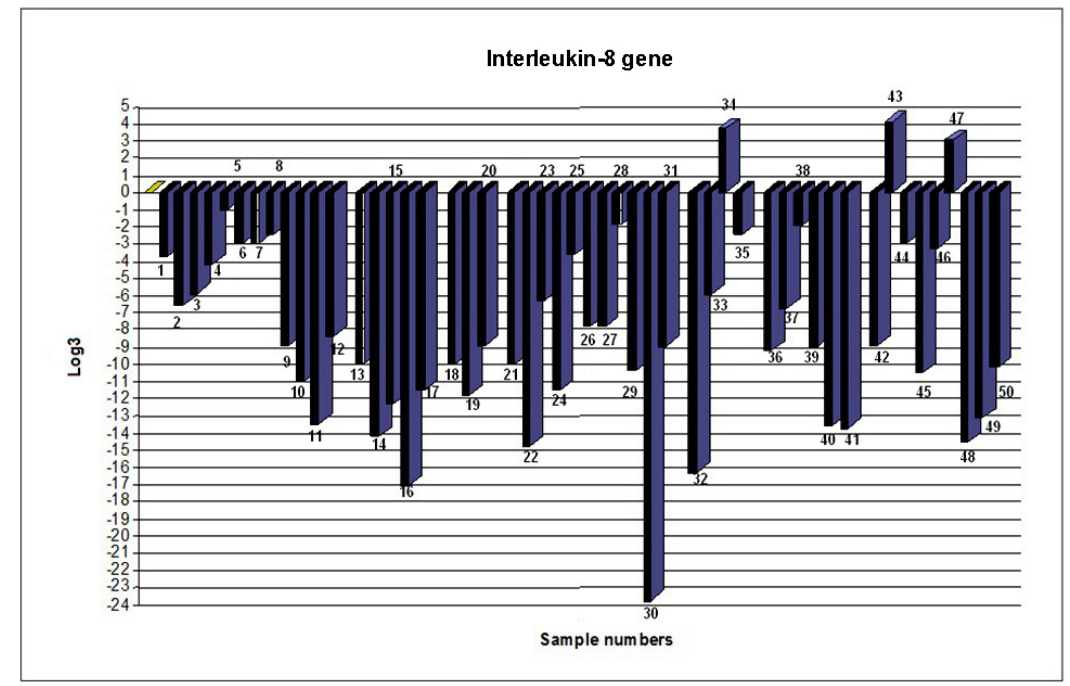

Figure 2. Expression of interleukin-8 in canine mammary neoplasia (black) and normal mammary tissue (1st bar; control) by real-time PCR. 
Comparing protein staining (immunohistochemistry) to gene expression (real-time PCR), gene overexpression was combined with moderate staining. The bitches in which gene overexpression was detected, survived for over 18 months. Gene overexpression was observed in cases with the most severe tumor type, especially carcinomas. The nine individuals diagnosed with complex carcinomas had low gene expression. Four of these animals had weak protein staining, 4 focal and only 1 strong.

\section{DISCUSSION}

The findings of this study suggest that IL- 8 can be used as a prognostic marker of canine mammary neoplasia. Although these results complement earlier studies on IL-8 expression in several types of cancer, including mammary cancer (Yoshimura et al., 1987), the present study seems to be the first one performed on dogs.

The prevalence of carcinomas was higher (78\%) than that found in other studies on mammary tumors in dogs, which report that $50 \%$ of these tumors are benign and $50 \%$ are malignant (Slater, 2007). This unexpected discrepancy is an interesting point that deserves further investigations.

The values found in the histological degree of differentiation have provided useful information on tumor prognosis. According to our findings, the survival rate decreased with increasing degree evaluated. Related findings were found in the article of Karayannopoulou et al. (2005), in which the number of deaths within the period of two years were $0 / 27(0 \%)$ for dogs with grade I carcinoma, 13/28 (46.4\%) for dogs with grade II carcinoma and 26/30 $(86.7 \%)$ for dogs with grade III carcinoma.

The low levels of gene expression (real-time PCR) found were correlated with moderate to strong IL-8 immunostaining. This is likely a consequence of post-transcriptional changes that alter IL- 8 synthesis. In contrast to earlier studies, we found that the IL- 8 gene was predominantly underexpressed in the samples tested, suggesting that the IL-8 protein in these cells play a protective role against tumor formation. This agrees with Lee et al. (2000), who studied IL-8 expression in human ovarian tumor cells and concluded that IL-8 can reduce tumor growth rate, suggesting that chemotherapy-induced IL- 8 overexpression may have a positive role in controlling tumor growth.

In the present study, we found that samples from 3 dogs that survived for over 18 months postoperative had IL-8 overexpression with moderate immunohistochemical staining, thus indicating that IL-8 may play a protective role in canine mammary cancer as well. Corroborating this hypothesis, high IL-8 expression in nude mice apparently inhibited tumor growth caused by a transplanted tumor of ER-negative breast cancer cells (Yao et al., 2007). Wang et al. (1996) reported that IL-8 could inhibit the proliferation activity of non-small carcinoma cells through autocrine and paracrine secretion. These results are, however, in disagreement with the literature, which indicates that the IL- 8 gene is activated in a metastatic phenotype through angiogenesis (Li et al., 1998; Knupfer et al., 2004).

Scientific evidence suggests that IL-8 is a key factor for the occurrence of metastatic breast cancer (Slater, 2007). Derin et al. (2007) assessed blood interleukin levels and the relationship with cancer prognosis, concluding that patients with metastatic breast carcinoma had high levels of IL-8 compared to non-metastatic patients. Freund et al. (2004) described that IL-8 was overexpressed in invasive breast cancer cells, and this was observed in cancer cells 
that show a higher transcriptional activity of IL-8 gene promoter.

In contrast to our findings, these authors observed that IL-8 overexpression was correlated to metastatic mammary carcinoma. Simeone et al. (2007) reported that high IL-8 expression promotes breast cancer metastasis. In addition to its relationship with angiogenesis, IL-8 is also associated with the metastatic phenotype and it promotes breast tumor cell potential, especially because this area receives a rich blood supply (De Larco et al., 2003; BobrovnikovaMarjon et al., 2004). Also, high levels of IL-8 confirm the potential of tumor aggressiveness (Zhou et al., 2006). Benoy et al. (2004) observed high levels of IL-8 in 67\% of patients with advanced breast cancer who survived for a shorter period.

Contrasting molecular expression and metastasis occurrence, $100 \%$ of the metastatic tumors showed gene underexpression. This supports the idea that gene overexpression is related to a favorable prognosis.

\section{CONCLUSION}

The present study shows that IL-8 expression possibly exerts a suppressive action on mammary cancer in female dogs, thereby playing a protective role against cancer. Univariate analysis revealed that IL-8 overexpression was associated with strong immunostaining, survival for 18 months and the absence of metastatic tendency. These findings raise the question of IL-8 suppressive action on canine mammary cancer. Further studies are necessary to corroborate the protective properties of IL-8 against canine mammary tumors.

\section{ACKNOWLEDGMENTS}

We thank Prof. Lilian Castiglioni for help in the development of the project; Prof. Felipe Augusto Ruiz Sueiro, Prof. Noeme S. Rocha and Prof. Cicero Meneghetti for support in reading and analyzing the slides; Prof. José Antônio Cordeiro for the statistical analyses, and Prof. Eny M. Goloni-Bertollo, Prof. Érika C. Pavarino-Bertelli and Prof. Eloisa H. Tajara for their advice. Research supported by FAPESP (Proc. \#05/51936-0).

\section{REFERENCES}

Allred DC, Harvey JM, Berardo M and Clark GM (1998). Prognostic and predictive factors in breast cancer by immunohistochemical analysis. Mod. Pathol. 11: 155-168.

Benoy IH, Salgado R, Van Dam P, Geboers K, et al. (2004). Increased serum interleukin-8 in patients with early and metastatic breast cancer correlates with early dissemination and survival. Clin. Cancer Res. 10: 7157-7162.

Bobrovnikova-Marjon EV, Marjon PL, Barbash O, Vander Jagt DL, et al. (2004). Expression of angiogenic factors vascular endothelial growth factor and interleukin-8/CXCL8 is highly responsive to ambient glutamine availability: role of nuclear factor-kappaB and activating protein-1. Cancer Res. 64: 4858-4869.

Brodey RS, Goldschmidt MH and Roszel JR (1983). Canine mammary gland neoplasms. J. Am. Anim. Hosp. Assoc. 19: 61-69.

Cordeiro JA (1987). Análises de Dependência. Relatório Técnico No. 48/87. Instituto de Matemática e Estatística UNICAMP, Campinas.

De Larco JE, Wuertz BR, Rosner KA, Erickson SA, et al. (2001). A potential role for interleukin-8 in the metastatic phenotype of breast carcinoma cells. Am. J. Pathol. 158: 639-646.

De Larco JE, Wuertz BR, Yee D, Rickert BL, et al. (2003). Atypical methylation of the interleukin-8 gene correlates strongly with the metastatic potential of breast carcinoma cells. Proc. Natl. Acad. Sci. U. S. A. 100: 13988-13993.

Derin D, Soydinc HO, Guney N, Tas F, et al. (2007). Serum IL-8 and IL-12 levels in breast cancer. Med. Oncol. 24: 163-168. Elston CW and Ellis IO (Editors) (1998). Assessment of Histological Grade. In: The Breast. Vol. 13. Churchill Livingstone, 
Edinburgh, New York, 356-384.

Ferreira E, Bertagnolli AC, Cavalcanti MF, Schmitt FC, et al. (2009). The relationship between tumour size and expression of prognostic markers in benign and malignant canine mammary tumours. Vet. Comp. Oncol. 7: 230-235.

Freund A, Jolivel V, Durand S, Kersual N, et al. (2004). Mechanisms underlying differential expression of interleukin-8 in breast cancer cells. Oncogene 23: 6105-6114.

Karayannopoulou M, Kaldrymidou E, Constantinidis TC and Dessiris A (2005). Histological grading and prognosis in dogs with mammary carcinomas: application of a human grading method. J. Comp. Pathol. 133: 246-252.

Knupfer H, Schmidt R, Stanitz D, Brauckhoff M, et al. (2004). CYP2C and IL-6 expression in breast cancer. Breast 13: 28-34.

Lee LF, Hellendall RP, Wang Y, Haskill JS, et al. (2000). IL-8 reduced tumorigenicity of human ovarian cancer in vivo due to neutrophil infiltration. J. Immunol. 164: 2769-2775.

Li Q, Bostick-Bruton F and Reed E (1998). Effect of interleukin-1 alpha and tumour necrosis factor-alpha on cisplatininduced ERCC-1 mRNA expression in a human ovarian carcinoma cell line. Anticancer Res. 18: 2283-2287.

Livak KJ and Schmittgen TD (2001). Analysis of relative gene expression data using real-time quantitative PCR and the $2^{-\Delta \Delta C t}$ Method. Methods 25: 402-408.

MacEwen EG (1990). Spontaneous tumors in dogs and cats: models for the study of cancer biology and treatment. Cancer Metastasis Rev. 9: 125-136.

Misdorp W, Else RW, Héllmén E and Lipscomb TP (1999). Histological Classification of Mammary Tumors of the Dog and the Cat. Armed Forces Institute of Pathology, Washington.

Monton M, Lopez-Farre A, Mosquera JR, Sanchez de ML, et al. (1997). Endogenous angiotensin II produced by endothelium regulates interleukin-1beta-stimulated nitric oxide generation in rat isolated vessels. Hypertension 30: 1191-1197.

Moulton JE (Editor) (1990). Tumors of the Mammary Gland. In: Tumors in Domestic Animals. 3rd edn. University of California Press, California, 518-550.

Perez Alenza MD, Pena L, del Castillo N and Nieto AI (2000). Factors influencing the incidence and prognosis of canine mammary tumours. J. Small Anim. Pract. 41: 287-291.

Queiroga F and Lopes C (2002). Tumores Mamários Caninos: Novas Perspectiva. In: Congresso de Ciências Veterinárias, Oeiras. Sociedade Portuguesa de Ciências Veterinárias, Lisboa, 183-190.

Schmidt A, Bengtsson A, Tylman M and Blomqvist L (2007). Pro-inflammatory cytokines in elective flap surgery. J. Surg. Res. 137: 117-121.

Schwaninger R, Rentsch CA, Wetterwald A, van der Horst G, et al. (2007). Lack of noggin expression by cancer cells is a determinant of the osteoblast response in bone metastases. Am. J. Pathol. 170: 160-175.

Simeone AM, Nieves-Alicea R, McMurtry VC, Colella S, et al. (2007). Cyclooxygenase-2 uses the protein kinase C/ interleukin-8/urokinase-type plasminogen activator pathway to increase the invasiveness of breast cancer cells. Int. J. Oncol. 30: 785-792.

Slater D (Editor) (2007). Oncology in Reproductive System. In: Manual of Small Animal Surgery. 2nd edn. Manole, São Paulo, 2566-2592.

Snoussi K, Mahfoudh W, Bouaouina N, Ahmed SB, et al. (2006). Genetic variation in IL-8 associated with increased risk and poor prognosis of breast carcinoma. Hum. Immunol. 67: 13-21.

Sorenmo K (1998). An Update on Canine Mammary Gland Tumors. In: Proceedings of the 16th Annual ACVIM Veterinary Medical Forum, San Diego, 387-388.

Sorenmo KU, Kristiansen VM, Cofone MA, Shofer FS, et al. (2009). Canine mammary gland tumours; a histological continuum from benign to malignant; clinical and histopathological evidence. Vet. Comp. Oncol. 7: 162-172.

Thomas E and Berner G (2000). Prognostic and predictive implications of HER2 status for breast cancer patients. Eur. J. Oncol. Nurs. 4: 10-17.

van't Veer LJ, Paik S and Hayes DF (2005). Gene expression profiling of breast cancer: a new tumor marker. J. Clin. Oncol. 23: 1631-1635.

Vazquez-Martin A, Colomer R and Menendez JA (2007). Protein array technology to detect HER2 (erbB-2)-induced 'cytokine signature' in breast cancer. Eur. J. Cancer 43: 1117-1124.

Wahl LM and Kleinman HK (1998). Tumor-associated macrophages as targets for cancer therapy. J. Natl. Cancer Inst. 90: 1583-1584.

Wang J, Huang M, Lee P, Komanduri K, et al. (1996). Interleukin-8 inhibits non-small cell lung cancer proliferation: a possible role for regulation of tumor growth by autocrine and paracrine pathways. J. Interferon Cytokine Res. 16: $53-60$.

Yao C, Lin Y, Ye CS, Bi J, et al. (2007). Role of interleukin-8 in the progression of estrogen receptor-negative breast cancer. Chin. Med. J. 120: 1766-1772. 
Yoshimura T, Matsushima K, Tanaka S, Robinson EA, et al. (1987). Purification of a human monocyte-derived neutrophil chemotactic factor that has peptide sequence similarity to other host defense cytokines. Proc. Natl. Acad. Sci. U. S. A. 84: 9233-9237.

Zhou S, Wang GP, Liu C and Zhou M (2006). Eukaryotic initiation factor 4E (eIF4E) and angiogenesis: prognostic markers for breast cancer. BMC Cancer 6: 231 .

Zuccari DAPC, Santana AE and Rocha NS (2001). Fine needle aspiration cytologic and histologic correlation in canine mammary tumors. Braz. J. Vet. Res. Anim. Sci. 38: 38-41.

Zuccari DAPC, Pavam MV, Terzian ACB, Pereira RS, et al. (2008). Immunohistochemical evaluation of e-cadherin, Ki-67 and PCNA in canine mammary neoplasias: correlation of prognostic factors and clinical outcome. Pesq. Vet. Bras. 28: 207-215. 